\title{
Editorial
}

\section{Advances in Remote Sensing to Understand Extreme Hydrological Events}

\author{
Dongkyun Kim $\mathbb{D D}^{1}{ }^{1}$ Minha Choi $\mathbb{D}^{2},{ }^{2}$ Jongho Kim, ${ }^{3}$ and Ungtae Kim $\mathbb{D}^{4}$ \\ ${ }^{1}$ Department of Civil Engineering, Hongik University, Seoul, Republic of Korea \\ ${ }^{2}$ Department of Water Resources, Graduate School of Water Resources, Sungkyunkwan University, Suwon, Republic of Korea \\ ${ }^{3}$ School of Civil and Environmental Engineering, University of Ulsan, Ulsan, Republic of Korea \\ ${ }^{4}$ Department of Civil and Environmental Engineering, Cleveland State University, Cleveland, OH, USA \\ Correspondence should be addressed to Dongkyun Kim; kim.dongkyun@hongik.ac.kr
}

Received 17 October 2019; Accepted 17 October 2019; Published 12 November 2019

Copyright (c) 2019 Dongkyun Kim et al. This is an open access article distributed under the Creative Commons Attribution License, which permits unrestricted use, distribution, and reproduction in any medium, provided the original work is properly cited.

Hydrological extreme events [1,2] often lead to catastrophes for humans [3] and the environment [4]. The identification, understanding, modeling, validation, and prediction of hydrological extreme events are crucial in preventing such catastrophes and eventually developing a system that is resilient to them, but such tasks are challenging. This is because it is difficult to obtain a comprehensive understanding of extreme events in which spatiotemporal characteristics vary significantly, and the corresponding damage that typically occurs over a spatial extent of several thousand kilometers.

The weather radar and the satellite-based remote sensing techniques are two major research branches to resolve these issues. Weather radar provides the near-real-time precise and accurate observation of precipitation over the spatial coverage encompassing several hundred kilometers. While traditional studies regarding weather radar have focused on the calibration [5, 6], bias correction [7], validation, and uncertainty estimation [8, 9] of radar measurements, recent studies investigated the topics of merging ground and radar precipitation data [10-12], storm movement tracking and forecast [13-15], application to urban flash flood and warning $[16,17]$, and design parameter estimation $[18,19]$. The satellite remote sensing techniques allow us to observe a variety of components of hydrological cycle at a global scale. They have been developed for the estimation of water and energy fluxes between the land surface and atmosphere in terms of space and time. The major water and energy fluxes are land surface temperature, soil moisture, evapotranspiration, snow water equivalent, and vegetation/land cover [20].

In addition, technologies regarding radar and satellite sensors and satellite launchers have been advancing remarkably. The X-band radar instruments have been developed to figure out the $\mathrm{Z}$ - $\mathrm{R}$ relationships based on the shape of the rain drops and to capture rainfall intensity at the spatial resolutions of a few meters within a few kilometers of radius [21, 22]; the acquisition period for optical and SAR satellite images is already getting as shorter as less than one day [23].

This dramatic advance in the remote sensing techniques will eventually revolutionize the design and management framework to make current anthropogenic systems more agile and efficient against natural disasters. For example, the radar-gauge merging techniques and the accumulating length of the radar precipitation records enable a more thorough understanding of the characteristics of extreme precipitation including their whole spatial pattern, temporal progress, and interactions with other environmental variables, which subsequently yields more realistic and costeffective design parameters [24] and agile real-time flood warning systems customized to the urban areas as small as several square kilometers [25].

In this era of abundant remote sensing data, the mission of hydrologists is evident: actively utilizing the data; extending the dimension of our understanding of nature; and returning the benefits to the human and environment. 


\section{Conflicts of Interest}

The editors declare that there are no conflicts of interest regarding the publication of this issue.

\section{Acknowledgments}

We would like to give our special thanks to all reviewers for their constructive comments to improve the quality of the submitted papers. The efforts of Dr. Dongkyun Kim to handle the submitted manuscripts and writing this editorial were financially supported by a grant (MOIS-DP-2015-05) through the Disaster and Safety Management Institute funded by Ministry of the Interior and Safety of Korean Government.

\section{Dongkyun Kim Minha Choi Jongho Kim Ungate Kim}

\section{References}

[1] M. L. Bernhardt, J.-L. Briaud, A. V. Govindsamy et al., "Mississippi river levee failures: June 2008 flood," International Journal of Geoengineering Case Histories, vol. 2, no. 3, pp. 127-162, 2011.

[2] J. Yang, D. Gong, W. Wang, M. Hu, and R. Mao, "Extreme drought event of 2009/2010 over southwestern China," Meteorology and Atmospheric Physics, vol. 115, no. 3-4, pp. 173-184, 2012.

[3] J. O. Ogutu and N. Owen-Smith, "ENSO, rainfall and temperature influences on extreme population declines among African savanna ungulates," Ecology Letters, vol. 6, no. 5, pp. 412-419, 2003.

[4] A. R. Gitlin, C. M. Sthultz, M. A. Bowker et al., "Mortality gradients within and among dominant plant populations as barometers of ecosystem change during extreme drought," Conservation Biology, vol. 20, no. 5, pp. 1477-1486, 2006.

[5] E. N. Anagnostou, M. N. Anagnostou, W. F. Krajewski, A. Kruger, and B. J. Miriovsky, "High-resolution rainfall estimation from X-band polarimetric radar measurements," Journal of Hydrometeorology, vol. 5, no. 1, pp. 110-128, 2004.

[6] M. N. Anagnostou and E. N. Anagnostou, Precipitation: Advances in Measurement, Estimation and Prediction, S. Michaelides, Ed., Springer, Berlin, Germany, 2008.

[7] D.-J. Seo, J. Breidenbach, and E. R. Johnson, "Real-time estimation of mean field bias in radar rainfall data," Journal of Hydrology, vol. 223, no. 3-4, pp. 131-147, 1999.

[8] R. V. Calheiros and I. Zawadzki, "Reflectivity-rain rate relationships for radar hydrology in Brazil," Journal of Climate and Applied Meteorology, vol. 26, no. 1, pp. 118-132, 1987.

[9] W. F. Krajewski and J. A. Smith, "Radar hydrology: rainfall estimation," Advances in Water Resources, vol. 25, no. 8-12, pp. 1387-1394, 2002.

[10] S. Sinclair and G. Pegram, "Combining radar and rain gauge rainfall estimates using conditional merging," Atmospheric Science Letters, vol. 6, no. 1, pp. 19-22, 2005.

[11] E. Goudenhoofdt and L. Delobbe, "Evaluation of radar-gauge merging methods for quantitative precipitation estimates," Hydrology and Earth System Sciences, vol. 13, no. 2, pp. 195-203, 2009.
[12] S. Ochoa-Rodriguez, L.-P. Wang, P. Willems, and C. Onof, “A review of radar-rain gauge data merging methods and their potential for urban hydrological applications," Water Resources Research, vol. 55, no. 8, pp. 6356-6391, 2019.

[13] L. Han, S. Fu, L. Zhao, Y. Zheng, H. Wang, and Y. Lin, "3D convective storm identification, tracking, and forecasting - an enhanced TITAN algorithm," Journal of Atmospheric and Oceanic Technology, vol. 26, no. 4, pp. 719-732, 2009.

[14] N. Peleg and E. Morin, "Convective rain cells: radar-derived spatiotemporal characteristics and synoptic patterns over the eastern Mediterranean," Journal of Geophysical Research: Atmospheres, vol. 117, no. D15, 2012.

[15] D. Tiranti, R. Cremonini, F. Marco, A. R. Gaeta, and S. Barbero, "The defense (debris Flows triggEred by storms-nowcasting system): an early warning system for torrential processes by radar storm tracking using a Geographic Information System (GIS)," Computers \& Geosciences, vol. 70, pp. 96-109, 2014.

[16] P. B. Bedient, A. Holder, J. A. Benavides, and B. E. Vieux, "Radar-based flood warning system applied to Tropical Storm Allison," Journal of Hydrologic Engineering, vol. 8, no. 6, pp. 308-318, 2003.

[17] J. A. Smith, M. L. Baeck, K. L. Meierdiercks, A. J. Miller, and W. F. Krajewski, "Radar rainfall estimation for flash flood forecasting in small urban watersheds," Advances in Water Resources, vol. 30, no. 10, pp. 2087-2097, 2007.

[18] F. Olivera, J. Choi, D. Kim, and M.-H. Li, "Estimation of average rainfall areal reduction factors in Texas using NEXRAD data," Journal of Hydrologic Engineering, vol. 13, no. 6, pp. 438-448, 2008.

[19] F. Lombardo, F. Napolitano, and F. Russo, "On the use of radar reflectivity for estimation of the areal reduction factor," Natural Hazards and Earth System Science, vol. 6, no. 3, pp. 377-386, 2006.

[20] T. J. Schmugge, W. P. Kustas, J. C. Ritchie, T. J. Jackson, and A. Rango, "Remote sensing in hydrology," Advances in Water Resources, vol. 25, no. 8-12, pp. 1367-1385, 2002.

[21] S. Y. Matrosov, K. A. Clark, B. E. Martner, and A. Tokay, "Xband polarimetric radar measurements of rainfall," Journal of Applied Meteorology, vol. 41, no. 9, pp. 941-952, 2002.

[22] M. Thurai, K. V. Mishra, W. Krajewski, and V. Bringi, "Evaluating the use of X-band specific attenuation for rainfall estimates using Iowa XPol-5 radar scans over a network of 25 rain gauges," in Proceedings of the 2019 13th European Conference on Antennas and Propagation (EuCAP), pp. 1-5, IEEE, Krakow, Poland, March 2019.

[23] Planet Team, "Planet application program interface," in Space for Life on Earth, Planet Team, San Francisco, CA, USA, 2017.

[24] J. Kim, J. Lee, D. Kim, and B. Kang, "The role of rainfall spatial variability in estimating areal reduction factors," Journal of Hydrology, vol. 568, pp. 416-426, 2019.

[25] S. Thorndahl, J. E. Nielsen, and D. G. Jensen, "Urban pluvial flood prediction: a case study evaluating radar rainfall nowcasts and numerical weather prediction models as model inputs," Water Science and Technology, vol. 74, no. 11, pp. 2599-2610, 2016. 

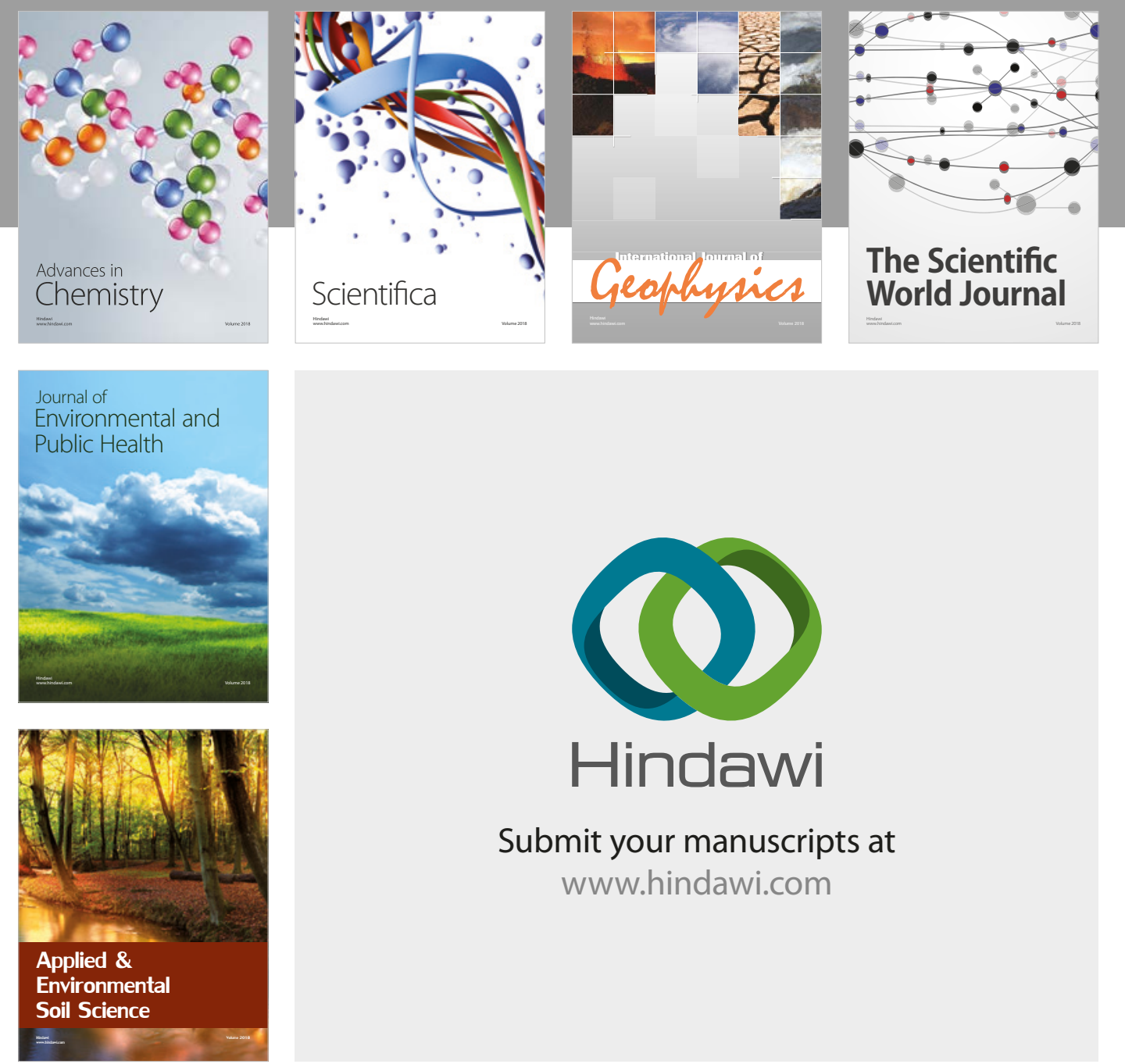

The Scientific

\section{World Journal}
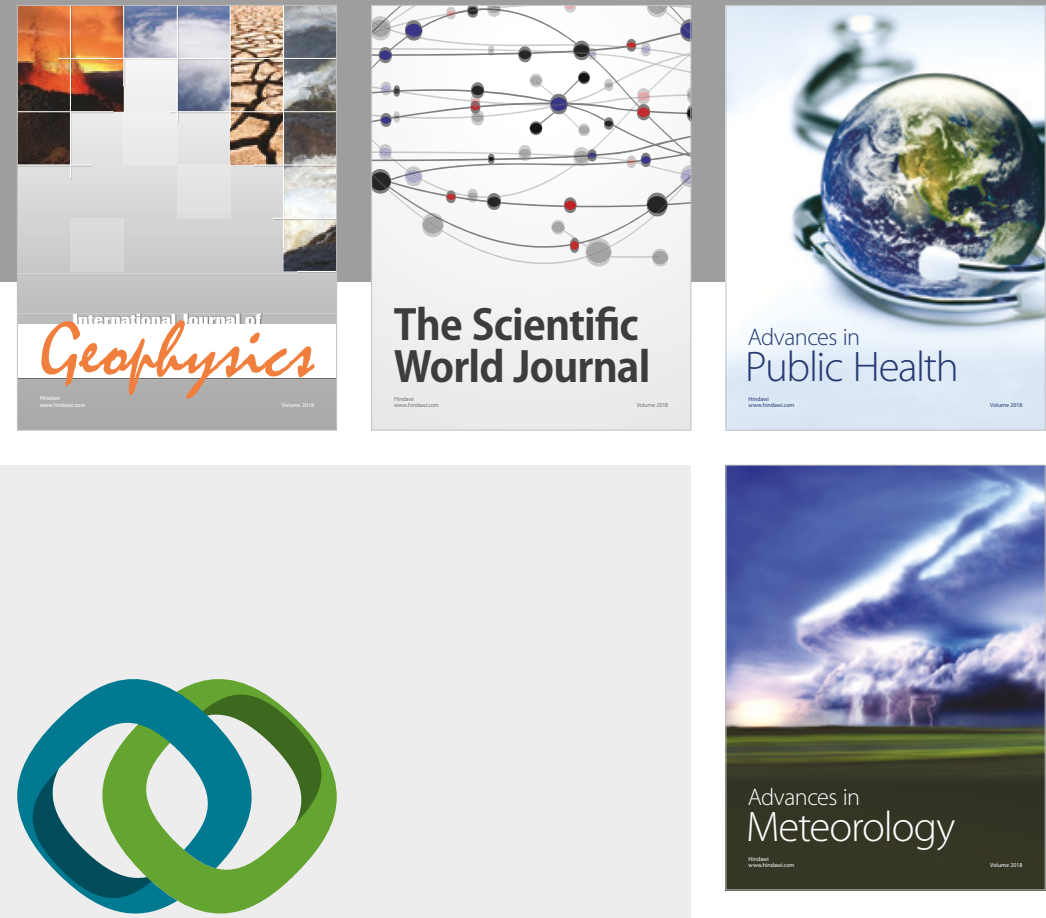

Advan

Public Health

\section{Hindawi}

Submit your manuscripts at

www.hindawi.com
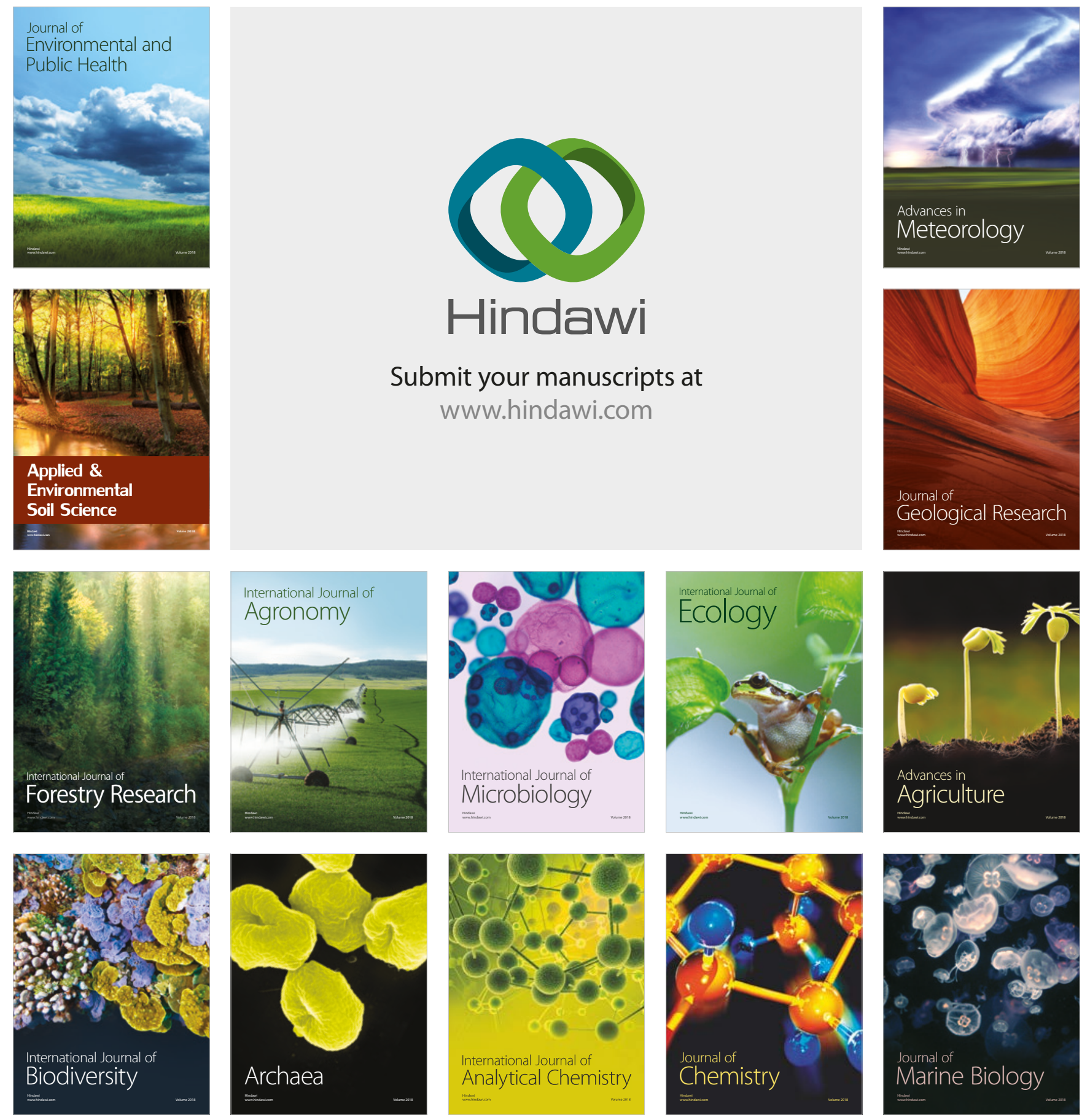